\title{
Human Optimal Functioning: The Genetics of Positive Orientation Towards Self, Life, and the Future
}

Gian Vittorio Caprara · Corrado Fagnani ·

Guido Alessandri · Patrizia Steca - Antonella Gigantesco •

Luigi Luca Cavalli Sforza · Maria Antonietta Stazi

Published online: 27 May 2009

(C) Springer Science+Business Media, LLC 2009

Erratum to: Behav Genet (2009) 39:277-284

DOI 10.1007/s10519-009-9267-y

Unfortunately one of the authors' names was abbreviated incorrectly in the contents listing and the affiliation section of this article. Instead of L.L.C. Sforza it should read L.L. Cavalli Sforza.

The online version of the original article can be found under doi:10.1007/s10519-009-9267-y.

G. V. Caprara $(\bowtie) \cdot$ G. Alessandri

Psychology Department, "Sapienza" University of Rome,

Via dei Marsi 78, 00185 Rome, Italy

e-mail: gianvittorio.caprara@uniroma1.it

C. Fagnani - A. Gigantesco - M. A. Stazi

Istituto Superiore di Sanità, Rome, Italy

P. Steca

University of Milan "Bicocca", Milan, Italy

L. L. Cavalli Sforza

Stanford University, Stanford, CA, USA 